\title{
Intramedullary Teratoma of the Thoracic Spinal Cord associated with Anomalies of the Vertebrae and Ribs - Case Report-
}

\author{
Masaki ShIMAUCHI, Yuzo YaMAKAWA, Nobuhiko MARUOKA \\ and Keisuke HAMADA*
}

Departments of Neurosurgery and *Pediatrics, Miyazaki Prefectural Hospital, Miyazaki

\begin{abstract}
An intramedullary spinal cord teratoma was diagnosed in a 4-year-old boy who presented with gait disturbance. A congenital thoracic cord tumor was suspected on the basis of neurological and radiological findings. Magnetic resonance imaging demonstrated a mass extending from the $\mathrm{C} 7$ to Th6 levels; its heterogeneous intensity suggested a teratoma. The tumor was subtotally removed via C6Th6 laminectomies. Histological examination showed a teratoma consisting of mature and immature tridermic elements. The postoperative course was uneventful and he was discharged without major neurological deficits.
\end{abstract}

Key words: teratoma, spinal cord neoplasm, congenital anomalies, endodermal-ectodermal adhesion syndrome

\section{Introduction}

The majority of teratomas are reportedly located in the sacrococcygeal region, ovary, testis, mediastinum and, rarely, in the central nervous system (CNS). ${ }^{5)}$ Teratomas of the CNS account for only about $2 \%$ of all teratomas, ${ }^{5}$ and most are intracranial; teratomas arising in the spinal cord are very rare. We recently encountered a patient with an intramedullary teratoma of the thoracic spinal cord associated with anomalies of vertebrae and ribs at the same level.

\section{Case Report}

In October of 1984 the mother of a 4-year-old boy noticed that he was dragging his left leg. The gait disturbance gradually progressed, and he was admitted to the Department of Pediatrics of our hospital on June 17, 1985. He was referred to the Department of Neurosurgery on July 1, 1985, with the diagnosis of spinal cord tumor.
The general physical examination was unremarkable. On neurological examination, painful rigidity of the neck, especially on motion, was noted. Paraparesis, more marked on the left, was the dominant feature and he was able to walk only with assistance. Deep tendon reflexes of the lower extremities were exaggerated, and Babinski's sign was positive bilaterally. Bowel and bladder functions were normal. Tests of sensory function were inconclusive because of his poor cooperation.

Results of routine hematological and chemical tests were normal, and serum $\alpha$-fetoprotein (AFP) and human chorionic gonadotropin (HCG) were within normal limits. A lumbar puncture yielded clear, watery cerebrospinal fluid (CSF); the opening pressure was $100 \mathrm{mmH}_{2} \mathrm{O}$. An intraspinal block was suggested by the Queckenstedt test. In CSF the cell count was $10 / \mathrm{mm}^{3}$ (lymphocytes) and the protein content was elevated to $100 \mathrm{mg} / \mathrm{dl}$; HCG was normal but AFP was elevated to $100 \mathrm{ng} / \mathrm{ml}$.

A chest $\mathrm{X}$-ray revealed scoliosis of the thoracic spine and bilateral forking of the 4th rib (Fig. 1).

\section{Received May 13, 1987; Accepted March 9, 1988}

Authors' present address: M. Shimauchi, M.D. and N. Maruoka, M.D., Department of Neurosurgery, Miyazaki Medical College, Miyazaki, Japan. 


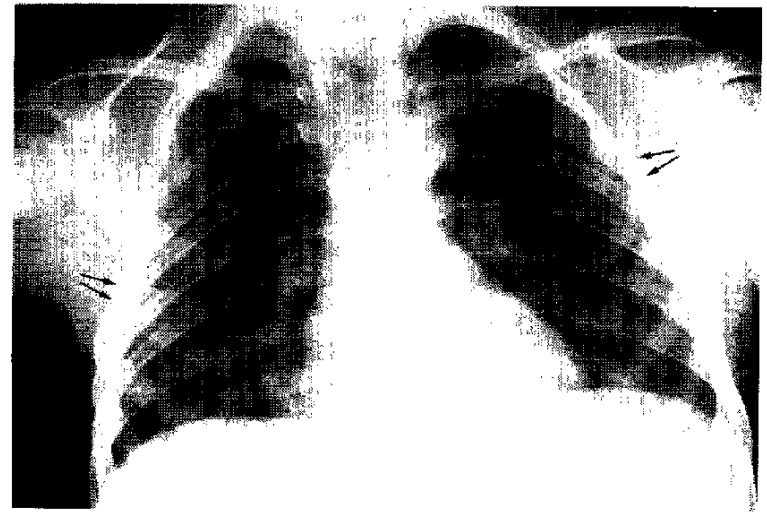

Fig. 1 Chest x-ray showing scoliosis of the thoracic spine and forking of the bilateral 4 th ribs (arrows).

Plain $\mathrm{x}$-rays of the spine demonstrated marked widening of the interpedicular space at the C6-Th5 levels, with erosion of the medial surface of both pedicles at Th3-4. The lateral view disclosed scalloping of the posterior surface of the bodies at Th3-4, and the spinous processes were displaced posteriorly at the Th2-4 levels. Spina bifida was apparent at Th5.

Metrizamide myelography, performed via lumbar puncture, revealed a block at the Th5 level (Fig. 2) and, on the lateral view, an intradural mass situated mainly behind the spinal cord. Metrizamide computed tomography (CT) myelography showed marked enlargement of the spinal canal above the Th6 level. The contrast medium did not advance beyond the Th3 level. At the Th4 level there was a region of low density ( $\mathrm{HU}-90)$ representing fatty tissue (Fig. 3). There were no large or spotty areas of high density, such as might be produced by a bone fragment or calcification. Intravenous contrast enhancement was not employed.

Magnetic resonance (MR) imaging with $0.1 \mathrm{~T}$ scanner (Mark-J, Asahi Medical Co., Tokyo) (spin echo sequences; echo time: $28 \mathrm{msec}$, repetition time: 500 $\mathrm{msec}$ ) showed the upper margin of the mass to be at the C7 level (Fig. 4). The lower portion of the mass displayed high intensity suggestive of fatty tissue, which corroborated the CT findings. Although the image was not clear, probably due to motion artifact, the upper portion of the mass showed isointensity. The preoperative diagnosis was teratoma composed of multiple tissues.

On July 16, 1985, C6 through Th6 laminectomies were performed. The Th5 lamina appeared to be duplicated on the right side, and the Th 3 and Th4 laminae were fused en bloc on the left. The dura mater was yellowish-white in color and was expanded and tense. When the dura mater was opened, a heterogeneous tumor was found at the C7-Th5

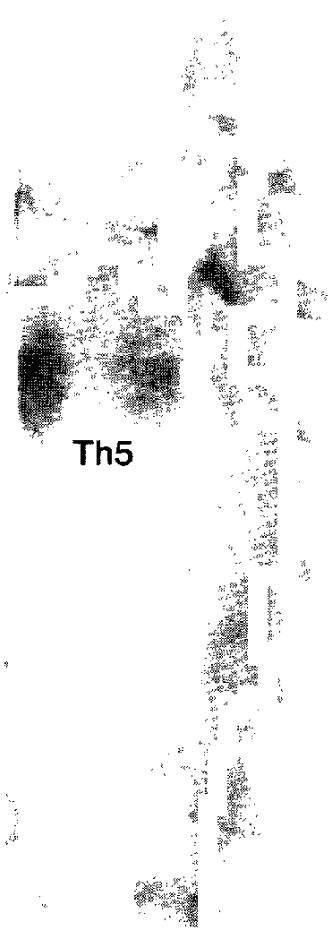

Fig. 2 Metrizamide myelogram showing a block at the Ths level.

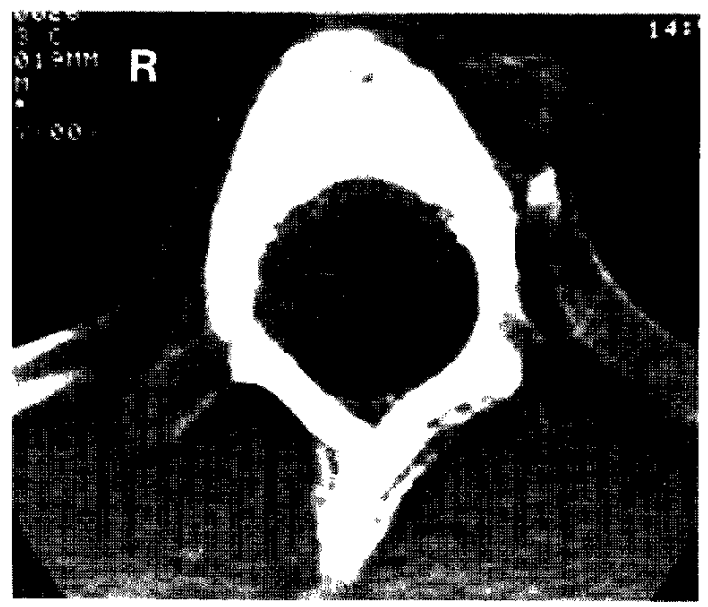

Fig. 3 Metrizamide CT myelogram demonstrating marked enlargement of the spinal canal and an area of low density ( $\mathrm{HU}-90)$, indicative of fatty tissue. 


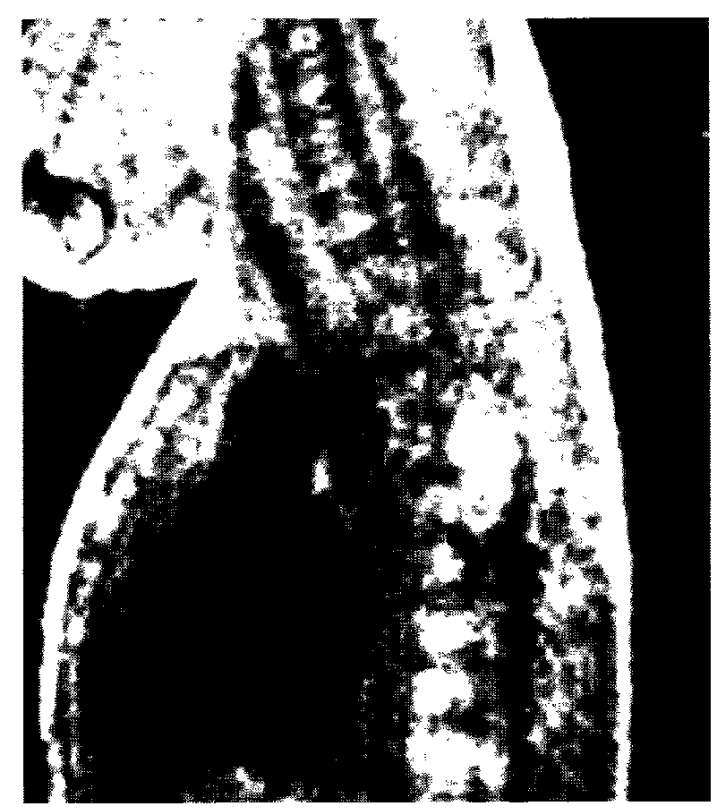

Fig. 4 MR image, spin echo sequences, demonstrating a heterogeneous mass from the $\mathrm{C} 7$ to Th5 levels. The lower portion of the mass exhibits high intensity, suggesting fatty tissue.

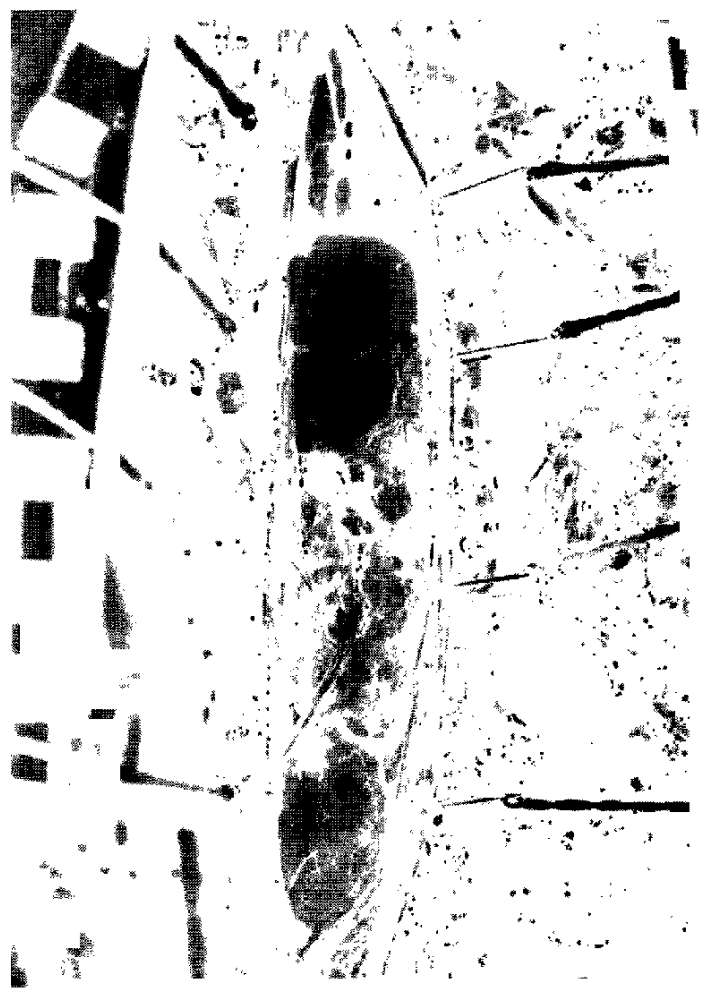

Fig. 5 Intraoperative photograph of the tumor at the C7-Th5 levels.

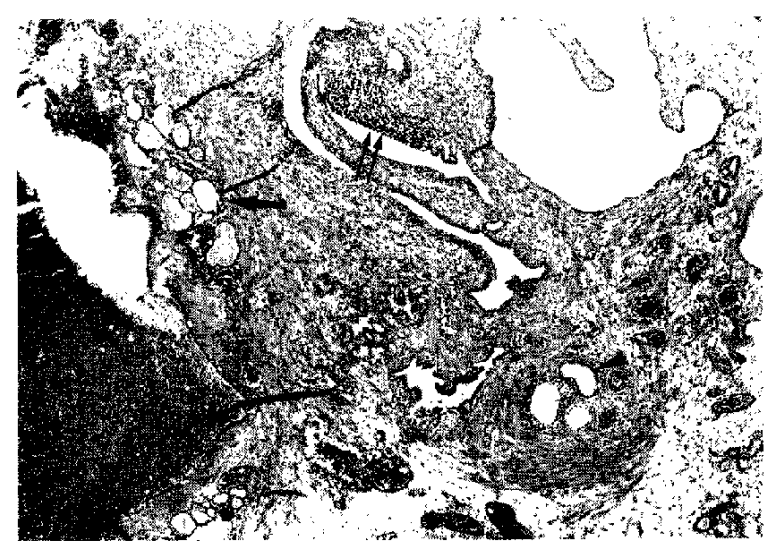

Fig. 6 Photomicrograph of surgical specimen showing mature fat, large and small vessels, columnar epithelium (arrowhead), thyroid-like glandular epithelium (arrow), and a cluster of small, immature cells with hyperchromatic nuclei (arrows). HE stain, $\times 60$.

levels (Fig. 5). The lower portion, which was pinkish-yellow in color, was largely composed of fatty tissue and contained many blood vessels. The upper portion consisted of a large, whitish, cylindrical cyst containing caseous material and hair. Most of the lower portion was situated within the spinal cord, whereas the upper component extended into the intradural extramedullary space.

The upper portion of the tumor was easily removed, together with its thin, membranous capsule, under the operating microscope. However, resection of the lower, apparently fatty portion was difficult. It was removed piece by piece, and small cysts and fragments of bone were recognized. At the Th4-5 levels, the demarcation between the tumor and the spinal cord was not clear, so further removal at this point was deferred. From an intraoperative perspective, the origin of the tumor appeared to be intramedullary at the Th4-5 levels. It was subtotally removed and the dura mater was tightly closed.

On histological examination, the tumor was found to be tridermic. The specimen contained well keratinized, stratified squamous epithelium with sweat and sebaceous glands, glial tissue, peripheral nerves, Pacinian corpuscles, striated muscle, bone, and mature fat. Columnar epithelium and thyroidlike glandular tissue were present within fibrous connective tissue. A cluster of small, immature cells with hyperchromatic nuclei was found in one part of the specimen (Fig. 6). Immunohistological staining with AFP and HCG antisera was negative. The histopathological diagnosis was teratoma containing mature and immature tissues. 
Immediately after surgery he was paraplegic and had bladder dysfunction, both of which gradually resolved. He was able to walk unassisted by the 39 th postoperative day. Radiation $\left({ }^{60} \mathrm{Co} ; 30 \mathrm{~Gy}\right)$ was administered locally. The AFP in CSF decreased to 10 $\mathrm{ng} / \mathrm{ml}$. At present, 2.5 years postoperatively, he is in good health and has no muscle weakness.

\section{Discussion}

Willis ${ }^{19)}$ defined teratoma as a tumor or neoplasm composed of multiple tissues that are foreign to the site in which it arises. Teratoma often occurs in gonads and extragonads, especially in the midline of the body. However, spinal cord teratoma is very rare. Sloof et al. ${ }^{16)}$ reported only two teratomas $(0.2 \%)$ in a series of 1322 spinal cord tumors in patients of all ages. In children, $33 \%$ of spinal cord teratomas occur in those under 1 year of age. ${ }^{17)}$ In Matson's series, ${ }^{(0)}$ teratomas accounted for 13 of 134 spinal tumors in children $(9.7 \%)$. The lumbar or lumbosacral region is the most frequent site, followed by the cervical region. ${ }^{17}$ )

Plain X-rays of spinal cord teratomas often show erosion of vertebral bodies and widening of the interpedicular space, with or without associated vertebral anomalies at the same level, such as spina bifida, ${ }^{3,4,6,8,10)}$ vertebral body fusion, ${ }^{1)}$ asymmetry of the vertebral bodies, ${ }^{14)}$ and diastematomyelia. ${ }^{18)}$ In our case, the tumor was located at the same level as the vertebral anomalies (spina bifida and fused laminae) and rib anomalies (forking). Forking of ribs is reportedly not rare, ${ }^{15)}$ but bilateral forking at the level of the spinal cord teratoma, as seen in our case, has never been reported, to our knowledge. The presence of such anomalies is useful in differentiating congenital spinal cord tumors, including teratomas, from other spinal cord tumors.

CT is very useful in making the preoperative diagnosis because teratomas exhibit variable density or calcification. ${ }^{11)}$ However, MR imaging is the most valuable diagnostic technique for teratoma. Norman et al. ${ }^{12)}$ noted that teratomas exhibit mixed high and low intensity, which indicates heterogeneity. Our findings corroborated theirs. Moreover, it is well known that sagittal MR image clearly delineates the margins of spinal cord tumors. With MR imaging, we were able to preoperatively determine not only the location and size of the tumor but also its pathological characteristics.

The origin of spinal cord teratoma is controversial. Kubie and Fulton ${ }^{97}$ hypothesized that teratomatous cysts represent the ependymal diverticulum of the central canal of the spinal cord. However, this theory does not explain the presence of muscle, bone, fat, and thyroid-like glandular tissue, which do not derive from neuroepithelium. Bucy and Buchanan $^{2)}$ proposed that teratoma arises from misplacement of multipotential germinal cells in early embryonic development. Rewcastle and Francoeur ${ }^{(4)}$ suggested that teratoma arises not from simple misplacement of normally developing somatic cells but from the fusion of two misplaced haploid germ cells, which supports the conclusions of Hunter and Lennox. ") They demonstrated the presence of "sex chromatin" bodies in the nuclei of the epithelial cells in two of four teratomatous cysts in male patients. The presence of sex chromatin bodies in the nuclei of the epithelial cells was explained by the hypothesis that fusion of two haploid $\mathrm{X}$ chromosomes would produce a "female" teratoma in a male patient.

Patients with spinal cord teratoma often have congenital skin abnormalities, such as dermal sinus, tufts of hair, or nevi, and vertebral anomalies at the same level. Ugarte et al. ${ }^{18)}$ reported two patients with true teratoma arising in juxtaposition to the spinal axis in association with diastematomyelia, and they reconciled this combination in terms of the anatomical spectrum of the "endodermal-ectodermal adhesion syndrome." "13) They also theorized that a persistent, abnormal neurenteric canal might offer a path for migrating germ cells. In our case, the origin of the intramedullary portion of the tumor (Th4-5) and the multiple anomalies of vertebrae and ribs (Th3-5) were at the same level. This segmental correspondence suggests that a teratogenic event, such as endodermal-ectodermal adhesion, might occur in the presomatic embryonic stage.

\section{Acknowledgment}

The authors wish to thank Professor K. Kinoshita, Department of Neurosurgery, Miyazaki Medical College, for his valuable comments.

\section{References}

1) Bakay L: Case records of the Massachusetts General Hospital (case 42502). N Engl J Med 255: 1153-1157, 1956

2) Bucy PC, Buchanan DN: Teratoma of the spinal cord. Surg Gynec Obstet 60: 1137-1144, 1935

3) Bucy PC, Haymond HE: Lumbosacral teratoma associated with spina bifida occulta. Report of a case with review of the literature. Amer $J$ Path 8: 339-349, 1932

4) Cybulski GR, von Roenn KA, Bailey OT: Intra- 
medullary cystic teratoid tumor of the cervical spinal cord in association with a teratoma of the ovary. Surg Neurol 22: 267-272, 1984

5) Gonzalez-Crussi F: Extragonadal teratomas, in: Atlas of Tumor Pathology, second series, fascicle 8 . Washington, DC, Armed Forces Institute of Pathology, 1980, pp 40-43

6) Hosoi K: Intradural teratoid tumor of the spinal cord. Report of a case. Arch Path (Chicago) 11:875883,1931

7) Hunter WF, Lennox B: Sex of teratomata. Lancet 2: $633-634,1954$

8) Ingraham FD, Bailey OT: Cystic teratomas and teratoid tumors of the central nervous system in infancy and childhood. I Neurosurg 3: 511-532, 1946

9) Kubie LS, Fulton JF: A clinical and pathological study of two teratomatous cysts of the spinal cord, containing mucus and ciliated cells. Surg Gynec Obstet 47: 297-311, 1928

10) Matson DD: Neurosurgery of Infancy and Childhood, ed 2. Springfield, CC Thomas, 1969, pp 647688

11) Nakayama K, Miyasaka $Y$, Matsumori K, Beppu T, Asao T: Spinal teratoma. Report of an elderly case. Neurol Med Chir (Tokyo) 23: 963-967, 1983 (in Japanese)

12) Norman D, Millis CM, Brant-Zawadzki M, Yeates A, Crooks LE, Kaufman L: Magnetic resonance imaging of the spinal cord and canal. Potentials and limitations. $A J R$ 141: 1147-1152, 1983

13) Prop N, Frensdorf EL, van de Stadt FR: A postvertebral endodermal cyst associated with axial deformities. A case showing the "endodermal-ectodermal adhesion syndrome." Pediatrics 39: 555562,1967

14) Rewcastle MB, Francoeur J: Teratomatous cysts of the spinal canal. With "sex chromatin" studies. Arch Neurol (Chicago) 11: 91-99, 1964

15) Sanger PW, Taylor FH, Robicsek F: Deformities of anterior wall of the chest. Surg Gynec Obstet 116: 515-522, 1963

16) Sloof JL, Kernohan JW, MacCarty CS: Primary Intramedullary Tumors of Spinal Cord and Filum Terminale. Philadelphia, WB Saunders, 1964, pp 1-20

17) Takeuchi J, Ohta $T$, Kajikawa $H$ : Congenital tumours of the spinal cord, in Vinken PJ, Bruyn GW (eds): Handbook of Clinical Neurology, vol 32. Amsterdam, North-Holland, 1978, pp 355-392

18) Ugarte N, Gonzalez-Crussi F, Sotelo-Avila C: Diastematomyelia associated with teratomas. Report of two cases. $J$ Neurosurg 53: 720-725, 1980

19) Willis RA: Pathology of Tumours, ed 4. London, Butterworth, 1968, pp 940-984

Address reprint requests to: M. Shimauchi, M.D., Department of Neurosurgery, Miyazaki Medical College, 5200 Kihara, Kiyotake-cho, Miyazaki-gun, Miyazaki 889-16, Japan. 